\section{LOOKING BACK ON 2016}

Every year, the BioTechniques editors reflect back on the year that was in science to identify important developments in life science techniques. Four methods trends emerged from our discussions of 2016: the extension of CRISPR/Cas9 genome editing applications, the expansion of human exome sequence databases, the widening use of nanopore sequencing technology, and the continuing questions regarding reproducibility in life science research.

CRISPR/Cas9 has come a long way in three short years-so much so that many were surprised this revolutionary technology did not win a Nobel Prize in 2016. Although it was still too early for that type of recognition, several new CRISPR/Cas9-based applications reported this year make it possible to quickly knock-out or knock-in genes singly or en mass in almost any organism. As a result, CRISPR/Cas9 is democratizing genetic analysis by enabling any organism to become a "model" organism.

Turning from genome editing to genome analysis, this issue of BioTechniques features a new "Practical Guide" by Dashti and Gamieldien presenting guidelines for prioritizing genetic variants for study based on how likely they are to play a role in a specific disease. In 2016, the Exome Aggregation Consortium (ExAC) reported the analysis of $>60,000$ human exomes, a huge windfall for researchers. As Dashti and Gamieldien note, identifying meaningful variants within such a large data set is no small feat; however, emerging new tools should make finding disease-causing variants much easier in the near future.

In 2016, access to next-generation sequencing (NGS) technology expanded. This is probably best reflected in the availability of nanopore sequencing instruments-low-cost, thumb drive-sized devices capable of decoding DNA rapidly inside or outside the lab. While not perfect yet, nanopore technology should continue to drive costs down and efficiency up in 2017 as usage increases and the technology is further refined.

Finally, reproducibility continues to be a hot topic within the life science community. Several initiatives launched in 2016 with the aim of enhancing research reproducibility and transparency. From better antibody validation to improved experimental design and statistical analyses, researchers, funders, companies, and journals are taking a hard look at how to improve the way research is performed and reported.

There were many potential picks for important 2016 trends, but we thought these four would be of particular interest to BioTechniques readers. Let us know what you think by sharing your own 2016 highlights with us at bioeditor@biotechniques.com.

BioTechniques is a peer-reviewed journal dedicated to the publication of original laboratory methods, related technical tools, and methods-oriented review articles that are of broad interest to scientists engaged in basic and applied life science research. Complete Instructions for Authors are available at bt.EditorialManager.com, BioTechniques' website for online manuscript submission. All manuscripts should be submitted at this site.

\section{BioTechniques Staff}

Editorial, Production \& Circulation

Editor-in-Chief: Nathan S. Blow, Ph.D.

Managing Editor: Amy R. Volpert

Senior Editor/Commercial Editor: Patrick C.H. Lo, Ph.D.

Senior Editor/News Editor: Kristie Nybo, Ph.D.

Contributing Writers:

Sarah A. Webb, Ph.D.

Production and Creative Manager,

BioScience Group: Genevieve McCarthy

Marketing Manager,

BioScience Group: Carisa McLaughlin

Sales \& Business Offices

Publisher: Tamaryn Hankinson,

tamaryn.hankinson@informa.com

Director, Operations and Audience Development,

BioScience Group: Nora Pastenkos

Global Sales Director/East Coast

Europe/Asia/Latin America: : Cheryl Wall, 978-356-0032

cwall@biotechniques.com

Midwest: Bob Zander, 312-925-7648

bob.zander@informausa.com

West Coast: Kayla McCutchan, 212-652-2667

kmccutchan@biotechniques.com

Manager, Advertising and Production Services, BioScience Group: Christine Briglia, christine.briglia@informausa.com

List Rental: Amy Miller • amiller@ibcusa.com

Reprints: biotechniques@fosterprinting.com

For subscriptions and inquiries, contact:

Phone: (847) 763-4930 Toll-free: (877) 232-2399

Email: biotechniques@halldata.com

\section{EditorialBoard}

Bill Brizzard, Indiana University Research and Technology Corp. Bruce Budowle, UNT Health Science Center Piotr Chomczynski, Molecular Research Center

Rita R. Colwell, University of Maryland-College Park and Johns Hopkins University

Joshua J. Coon, University of Wisconsin-Madison

Manel Esteller, Spanish National Cancer Centre (CNIO)

Jeffrey Felton, Western University of Health Sciences

Ron M. Fourney, Royal Canadian Mounted Police

Ivar Giaever, Rensselaer Polytechnic Institute

Richard A. Gibbs, Baylor College of Medicine

Erica A. Golemis, Fox Chase Cancer Center

Peter M. Gresshoff, The University of Queensland

Yoshihide Hayashizaki, RIKEN

Jörg Hoheisel, German Cancer Research Center

Leroy Hood, Institute for Systems Biology

Paul Keim, Northern Arizona University

Pui-Yan Kwok, University of California, San Francisco

Rachael L. Neve, Massachusetts Institute of Technology

Peter J. Oefner, University of Regensburg

Stephen W. Paddock, University of Wisconsin-Madison

Scott D. Patterson, Amgen, Inc.

Leonard F. Peruski, Jr., Centers for Disease Control

John Quackenbush, Harvard School of Public Health

Joshua Z. Rappoport, Northwestern University School of Medicine

Pier Giorgio Righetti, Polytechnic University of Milan

John Rossi, City of Hope

Herbert P. Schweizer, Colorado State University

Jay Shendure, University of Washington

Barton Slatko, New England Biolabs

Steve S. Sommer, MEDomics, LLC

Igor Stagljar, University of Toronto

Mathias Uhlén, The Royal Institute of Technology

Timothy Veenstra, SAIC-Frederick, Inc.

Kent E. Vrana, Penn State College of Medicine

Michael Weiner, AxioMx 